\title{
Telemedicine and primary care obesity management in rural areas - innovative approach for older adults?
}

\author{
John A. Batsis ${ }^{1,2,3,4,5,6^{*}}$, Sarah N. Pletcher ${ }^{2,7}$ and James E. Stahl ${ }^{1,2}$
}

\begin{abstract}
Background: The growing prevalence of obesity is paralleling a rise in the older adult population creating an increased risk of functional impairment, nursing home placement and early mortality. The Centers for Medicare and Medicaid recognized the importance of treating obesity and instituted a benefit in primary care settings to encourage intensive behavioral therapy in beneficiaries by primary care clinicians. This benefit covers frequent, brief, clinic visits designed to address older adult obesity.

Discussion: We describe the challenges in the implementation and delivery into real-world settings. The challenges in rural settings that have the fastest growing elderly population, high obesity rates, but also workforce shortages and lack of specialized services are emphasized. The use of Telemedicine has successfully been implemented in other specialties and could be a useful modality in delivering much needed intensive behavioral therapy, particularly in distant, underresourced environments. This review outlines some of the challenges with the current benefit and proposed solutions in overcoming rural primary care barriers to implementation, including changes in staffing models.
\end{abstract}

Conclusions: Recommendations to extend the benefit's coverage to be more inclusive of non-physician team members is needed but also for improvement in reimbursement for telemedicine services for older adults with obesity.

Keywords: Obesity, Weight loss, Medicare, Telemedicine, Primary care

\section{Background}

The growing epidemic of obesity affects over $35 \%$ of adults $\geq 65$ years in the United States [1] and is associated with serious health risks [2], including increased risk of functional impairment [3], nursing home admission [4], health care costs [5], and early mortality [6]. The disparities in obesity prevalence are even more apparent in rural areas [7] where older adults are the fastest growing segment of the population at risk for this disease [8]. The degree of excess adiposity is compounded by the onset of age-related loss of both muscle mass and quality, termed sarcopenia, that synergistically further impairs function [9]. Cost-effective strategies are needed to address this problem. Primary care practitioners are the

\footnotetext{
* Correspondence: john.batsis@gmail.com

${ }^{1}$ Section of General Internal Medicine, Dartmouth-Hitchcock Medical Center, 1 Medical Center Drive, Lebanon, NH 03756, USA

${ }^{2}$ Geisel School of Medicine at Dartmouth, Hanover, NH, USA

Full list of author information is available at the end of the article
}

first line for both primary and secondary obesity prevention efforts but must be equipped with adequate tools, training, and capacity to provide appropriate care [10-14]. Large-scale trials such as the Diabetes Prevention Program [15] and the Look-AHEAD [16] trials have been shown to be effective in achieving sustained weight loss, following a frequent, structured behavioral intervention. However, intensive structured behavioral interventions are often impractical to implement in primary care settings due to workforce shortages and lack of specialized resources, and when feasible, the evidence remains weak [17]. Only 12 randomized controlled trials have delivered intensive face-to-face counseling in a recent systematic review [17], yet, none involved the use of primary care practitioners (PCPs). In older adults, even less quality evidence exists with a recent systematic review finding only 6 randomized controlled trials of weight loss interventions, and similarly, none were conducted in a primary care setting [18]. The purpose of this current manuscript 
is to describe the impact and implementation challenges of the new Medicare Obesity Benefit (MOB) Regulatory Coverage determination in the United States. To our knowledge, little has been written on how it impacts primary care practices and how novel delivery modalities could be integrated to ensure its optimal effectiveness in delivering high quality obesity care.

\section{Medicare obesity benefit}

To encourage PCPs to deliver high quality obesity care in Medicare beneficiaries, the Centers for Medicare and Medicaid Services (CMS) introduced a regulatory coverage benefit in November 2011 [19]. This benefit was designed to reimburse PCPs for delivering up to 22 visits of intensive behavioral therapy (IBT) for weight loss within a primary care setting over a period of 12 months. Beneficiaries are required to lose $3 \mathrm{~kg}$ of weight during the first 6 months to remain eligible. Medicare requires the use and documentation of motivational interviewing using the 5 A's approach (Assess, Advise, Agree, Assist, Arrange) [20] as well as measurement of height and weight at each visit.

In arriving at these regulations, behavioral trials specifically focusing on older adults and weight-loss induced complications specific to this population such as sarcopenia or bone loss [21] were not addressed. CMS recognized the importance of reimbursement in a primary care setting as imperative to its success. The benefit currently covers physicians, associate providers and clinical nurse specialists but is not extended to others integrally involved in behavior change, for example, exercise physiologists, behavioral psychologists, or dieticians. The very slow uptake in practices implementing the MOB is likely due to practice management issues, insufficient reimbursement, the high frequency of visits, and an infrastructure that cannot support this benefit [22]. Our group identified only 46,821 Medicare beneficiaries $(0.17 \%)$ who availed themselves of the benefit in 2013, accounting for 101,290 claims (mean claims/beneficiary 2.16) [23].

\section{Implementation challenges of the medicare obesity benefit in rural areas}

Despite the availability and lack of utility of the MOB, we are concerned that its implementation within a rural primary care setting poses even more striking challenges. Below we outline some of the major barriers related to the workforce, transportation, and reimbursement issues.

\section{a. Workforce shortages \& lack of specialized services}

To meet growing demand, the United States will need between 20,400-35,000 additional PCPs by 2020 [24]. Most of this demand is in response to gradual population growth and aging [24]. While PCPs must have broad medical expertise, the frequency of delivering such face-to-face visits into an existing, overburdened practice makes implementation of the MOB very difficult. We believe that trying to implement this service under the current primary care workforce structure could potentially result in a real service gap potentially exacerbating existing provider burnout [25-27]. For instance, a PCP working 40 face-to-face hours per week with a patient panel of 2,000 patients may have 600 patients with obesity ( $30 \%$ obese). Assuming 30\% are Medicare beneficiaries $(n=180)$, if $50 \%$ fully utilized the benefit ( $n=90$ ), 29,700 $\min$ ( $495 \mathrm{~h}$ or $\sim 62$ working days) per year would be needed to deliver the benefit in full. This parallels the time needed for providing other preventive services [28]. Because time is finite, considerable tradeoffs in a day-to-day practice would need to occur. To fulfill one benefit, another may be lost as the current workforce and demands suggest that there is not enough provider capacity to meet the demand in primary care $[28,29]$. This is exacerbated in rural areas which also lack specialized services in part due to poor recruitment and retention [14]. Lack of nursing staff, dieticians and exercise therapists, all integral parts of the multidisciplinary team are critically needed to deliver comprehensive care [30].

\section{b. Transportation challenges}

Transportation and long-distances are barriers to health care services in rural areas [31-34] which leads to higher direct and indirect costs to both the patient and the system [5]. This can create difficult choices where people are prompted to ask their "willingness-to-pay" for the service in either time or money; whether patients will consider the trade-offs to gain the benefits of this service worth the cost [35]. Efficient, rural patient-centered transportation systems are lacking [36] and can lead to considerable stress for patients, families and caregivers. Distances between a patient's home and primary care practice may be acceptable for occasional, intermittent visits; however long travel distances for a short 15 min MOB visit may be problematic, a barrier that can be compounded by weather-related concerns. Distance is known to be an important factor in seeking healthcare in rural veterans [37] and other populations [38-42], increasing the risk of not returning for care. Inequalities to access to care have even been observed elsewhere, including Japan [43]. Our review of the literature did not find any studies specifically examining a relationship between distance and weight loss or obesity care.

\section{c. Poor Reimbursement mechanisms}

As with other venues, reduced reimbursement rates and rising operating costs have forced an increased 
number of practices to accept fewer Medicare/Medicaid patients creating challenges in access for these at risk populations [44]. The current reimbursement for the G0477 code (the MOB) is $\$ 27$ per session. We believe that alternative reimbursement models are needed to address this service gap, especially from Medicare, that places value on preventive care and management of chronic illnesses. Whether the current reimbursement system can sufficiently maintain a financial viable practice remains unclear.

\section{Telemedicine and obesity health promotion}

Telemedicine may be a useful modality to overcome a number of these aforementioned barriers. It has the potential to increase delivery of the MOB to a larger number of rural primary care practices, circumventing geographic challenges and patient mobility impediments in older, obese adults. While Telemedicine can be defined broadly, we define it as a remote, two-way, video-conferencing that substitutes for face-to-face visits. An increased reliance on universal technology availability makes Telemedicine a potentially viable option to accommodate visual, physical, hearing and cognitive impairments even in rural, older adults $[20,21]$. A number of successful ambulatory services have provided specialist advice using Telemedicine all of which have shown favorable patient outcomes, satisfaction and costs [45-47]. Specific to older adults, much of ambulatory care that has used telemedicine has serviced neurology or psychiatry consultations [48] and focused on the cognitive aspect of the comprehensive geriatric assessment. Telemedicine clinical trials and its research base using older adults is uncommon [49]. With the limited number of PCPs and geriatricians $[50,51]$, partnering with other providers for a brief clinical interaction without ongoing management may be more practical option.

Surprisingly, few studies have evaluated the use of Telemedicine in delivering weight loss interventions. One group has evaluated weight management delivered using Telemedicine in older adults in the IDEATel project [52]. Subjects were elderly Medicare beneficiaries in rural upstate New York with diabetes, $65.8 \%$ of which had a BMI $\geq 30 \mathrm{~kg} / \mathrm{m}$ [2]. Each subjects had a televisit with a dietician or nurse educator every 4-6 weeks. The findings noted a reduction in waist circumference of $1.2 \mathrm{~cm}$ and an improvement in their diet and exercise knowledge. The authors noted that telemedicine visits could successfully be used to establish behavior change goals [53]. In separate care delivery models, telemedicine has been successful in rural areas using diabetes nurse educators and specialists working with patients and primary care providers [54, 55], even in elderly Medicare beneficiary patients [56]. We advocate further systematic evaluation in broadening telemedicine-based interventions to rural areas that will ascertain overall effectiveness of the intervention.

The majority of Telemedicine obesity studies, to our knowledge, have focused on pediatric populations. A systematic review of pediatric weight management using Telemedicine identified 4 studies and suggested that Telemedicine may be promising for rural families with limited access to treatments. The results were associated with high patient satisfaction [57-60] but no differences in weight or other outcomes $[57,59,61]$. After program implementation, telemedicine increased the number of persons willing to participate in rural areas [61], potentially leading to a substitution of outreach clinics [62]. A separate residential obesity program in obese younger children noted a reduction in BMI with a positive effect on weight reduction and on long-term stabilization of weight [63].

Among the studies conducted in a general adult obesity population, Shaikh's group used Telemedicine to deliver obesity consultations to rural adults from a University-based center. Results noted improvements in diet, activity levels, and favorable changes in weight [64]. This same study group identified barriers in rural health clinics for delivering obesity interventions. Their findings suggested a lack of local weight management programs, lack of family involvement yet a distinct interest in providing care using Telehealth methods [65]. An evaluation of a home Telehealth program on weight maintenance after a group-based weight loss program did not demonstrate significant differences in weight $(0.6 \mathrm{~kg}$ in the intervention vs. $0.0 \mathrm{~kg}$ in the control), nor did it demonstrate other secondary outcome differences in diet, physical activity, social support or self-efficacy [66]. The successful Veterans Affairs MOVE! Weight Management program encountered difficulties when it was implemented in rural environments [67]. This intervention consisted of 12 weekly classes delivered using videoconferencing compared to a control group showing a mean difference of $-5.5 \pm 2.7 \mathrm{~kg}(-8.0,-3.0 ; p<0.001)$ of weight loss. In Taiwan, a 12-week program of videoconferencing in subjects aged 18-45 years for weight-loss led to a mean weight reduction of $5.9 \mathrm{~kg}$ with improvement in metabolic parameters [68]. Telehealth has also been found to be helpful for long-term weight loss maintenance with no significant changes in weight following the initial weight-loss program [69].

\section{Using telemedicine within the framework of the medicare obesity benefit in rural areas}

While future research is needed in older adults, telemedicine potentially can address gaps in primary care service coverage in rural areas to overcome the hurdles of reduced widespread implementation of the MOB. 
a. Addressing workforce issues and improving access to services:

The maldistribution of the workforce has accounted for, in part, the geographic variation in health outcomes between rural and urban populations [13, 67]. Established teleradiology and tele-ICU have successfully allowed a rapid diagnosis of conditions that smaller critical access hospitals cannot manage. Tele-stroke models that allow distant provider to provide stroke care under the advice of a stroke team have shown improved costeffective outcomes [70]. Canada has focused on using Telehealth to improve accessibility of health services in remote areas by providing consultations, case discussions and clinical support all of which may increase a clinician's ability to care for more individuals [71, 72]. Educating PCPs for specific populations can result in improved adherence to evidence-based guidelines and clinical outcomes [71].

Telemedicine can be adapted for obesity care. Traditional obesity counseling is delivered by office-based physicians, who have considerable gaps of knowledge in obesity therapies and management. Furthermore, PCPs have little time to deliver reasonable behavioral strategies to alter nutritional and lifestyle habits. Blanket statements are often the norm and PCPs perceive that a lack of time, educational materials and knowledge account for poor care [73]. One means of task-shifting within busy primary care environments would be to deliver the MOB using other healthcare personnel, including health coaches, dieticians and peers. Despite the potential for cost-savings, improved patient satisfaction, and reduced opportunity costs, many payers still do not reimburse for telemedicine nor do they reimburse for services rendered by allied health staff. This parallels that observed within the structure of the MOB which only permit incident-to billing encounters for non-provider staff, such as counsellors, nurses, or health coaches.

Peer health coaches can extend the capacity of existing practices in providing additional self-managing support for patients. This model has successfully been used in diabetic populations [74]. The Diabetes Prevention Lifestyle program was delivered by lay health educators and conducted in senior centers. This group had significantly greater percent weight loss $(3.8 \%$ vs. $0.2 \%)$, with $>38 \%$ losing $>5 \%$ baseline weight [53]. Recognizing the PCPs ability to effect changes in behavior and weight, the Think Health! Study, which was based upon the Diabetes Prevention Program, grouped PCP visits with lifestyle coaches every four months. These authors found that 22.5 vs. $10.2 \%$ lost weight more than $5 \%$ of their baseline weight in the intervention group, suggesting the importance of a moderate-intensity lifestyle coaching to facilitate weight loss [75]. Peer coaching using 12 group and
12 individual contacts demonstrated a mean loss of 5\% weight in 27\% of African American participants [76]. A pilot evaluation of older adults completing a 14-week intervention demonstrated high retention and participation rates as well as significant improvements in preand post- fitness levels based on a peer-mentoring model [77]. Others have pilot tested peer (individual and group) support and showed considerable potential of health coaches providing ongoing support, accountability, and information to support behavioral change. To date, there remains very little in terms of health coaching in the obesity literature.

Dietician-led telemedicine interventions have also been explored [78]. The dietician can be employed by a center that has the capacity to deliver obesity interventions. This is in contrast to rural centers that face recruitment challenges. Dieticians can not only train professionals locally in remote facilities, but can directly provide education to target populations at that site requiring further intervention. In fact, a nutrition telemedicine intervention provided support to patients on the Marshall Islands by remotely demonstrating acceptance and no lack of reservations by patients or providers [78]. Telemedicine can widen the available pool of available providers, not only across the country but across the world.

\section{b. Overcoming transportation barriers}

Delivering the $\mathrm{MOB}$ in a home-based setting has considerable potential advantages as it minimizes patient travel time, missed work, costs and risks associated with travel. Patients can use existing home-based technologies such as personal computers or tablets and obtain medical care and counseling without the need to leave their homes, reducing the risk for high risk elderly to fall, particular during the winter $[79,80]$. Seniors on fixed incomes participating in such programs may reduce the cost of associated travel and other indirect costs. An often overlooked advantage of home medical care practiced through telemedicine is that it may encourage the importance of self-care behaviors, improved compliance to healthcare regimens, improve satisfaction and increased empowerment to patients suffering from chronic illness and diseases allowing them to take an active role in their own care [81, 82]. Aging in place enhances the likelihood to improve one's health, quality of life and be engaged in their communities, particularly at a time where one has access to such remote technologies in the comfort of one's home setting [83]. The delivery of MOB using such novel technologies has considerable potential to improve important quality of life and medical outcomes in an older adult population. 
c. Broaden reimbursement mechanisms:

Telemedicine may be a reasonable substitute for faceto-face, hands-on encounters for consultation, office visits, individual psychotherapy and pharmacologic management by providing reimbursement at the same rates using a Telehealth modifier GT-via interactive audio and video telecommunications system). The G0477 face-toface behavioral counseling code for obesity is a covered telemedicine service within a primary care setting [19]. However, all beneficiaries receiving the service must be: i) physically located at an eligible facility located outside of a MSA; ii) the facility must be within a rural health professional shortage area; iii) the facility must be within a rural census tract; iv) the facility must be participating in a Telemedicine demonstration project; v) residing in one of these areas. There is no limitation on the physical location of the health professional delivering the service, although licensing may be a barrier to care. For Medicaid patients, reimbursement of services must satisfy federal requirements of efficiency economy and quality of care. Each state has the flexibility to cover to the extent of the medical care, including the types of telemedicine, where in the state, how it is provided, the types of practitioners and the fees that they will reimburse. The absence of a consistent, comprehensive policy for reimbursement is a serious obstacle to integration of Telehealth.

Home-based video-conferencing care can be a reasonable, cost-effective alternative that we believe should be reimbursable, particularly for rural, older adults. Medicare does not currently reimburse for remote patient monitoring services or services rendered outside of the geographic constraints listed above. We propose that the encounter should be reimbursed according to usual charges if the patient is physically present in their home setting. This may improve patient satisfaction, compliance and reduce overhead in the clinical infrastructure. Transitioning from fee-for-service to value-based payments (non-fee for service models) are needed that favor technologies to improve quality of patient care and reduced costs.

As with the MOB, there are limitations in the types of health professionals that can claim reimbursements for remote services, including physicians, associate providers or clinical nurse specialists. Section 1895(e) of the Act states that Telehealth services are outside the scope of the Medicare home health benefit and home health PPS, hence not providing coverage or payment for services provided via a telecommunications system. We would strongly urge policy makers to allow allied-health professions bill for telemedicine services under the auspices of the MOB.

\section{d. Telemedicine vs. other potential modalities?}

A number of other emerging models have demonstrated potential efficacy in achieving weight loss. Befort focused on rural participants using two distinct interventions: one involving a similar intensive face-to-face behavioral framework but included pre-packaged meals using a counsellor, and a second cluster randomized trial of an RN-health delivered phone counseling intervention, the results which have not been published [84, 85]. Others have evaluated differences in telephone counseling vs. in-person care [86, 87], internet-based applications [88, 89], or through a cooperative extension [90]. While each of these have the potential for weight loss, none have been evaluated within a primary care setting infrastructure, nor have they addressed specific rural barriers to transportation and access to care that can be problematic for older adults. Telephone monitoring may be problematic in a population at risk for hearing impairment [91]; older adults often require visualization to make sense of words $[91,92]$. The potential effectiveness of telemedicine is unclear but holds potential to overcome specific rural barriers and sensory challenges specific to older adults. Future research needs to evaluate and compare the differences between telemedicine and face-to-face counseling.

\section{Challenges in telemedicine implementation}

We recognize that there are a number of implementation challenges with a telemedicine-delivered MOB (see Table 1), of which we highlight a number of examples below. These can be categorized from an organization, technological, and geriatric-specific level:

\section{a. Organizational}

Prior to implementation, payors, clinical staff, and patients should be willing to consider such a system by making it a financially viable model for all. First, organizations must be willing to identify that telehealth is a priority in improving access for their patients. Second, practical challenges including overhead costs of the telemedicine infrastructure, including initial set-up and upgrades, at the delivering and receiving ends need to be considered and integrated into a business plan. Third, the organization needs to ensure appropriate billing and capturing of encounters. Low reimbursement continues to be problematic for long-term sustainability of telemedicine systems within a fee-for-service model. A full economic analysis is needed prior to engaging in such a venture. Fourth, for providers that are not familiar with such an infrastructure, continual reassurance is needed that telemedicine is patient-centered, and is associated with high satisfaction similar to face-to-face endeavors 
[93, 94]. Lastly, all team members should engage in a quality assurance model that provides immediate feedback that ensures continual feedback [62].

\section{b. Technological}

While broadband access within rural areas has increased considerably in the past few years, it still lags its urban counterparts [95]. High-speed cable internet, which has greater bandwidth capabilities and a more reliable signal than satellite, may be available at community-based or critical access hospitals, but may not be available with full reliability in small rural clinics or in the homes of patients. In one study in Australia, 25\% of all consultations experienced internet connection dropping and sound issues, concluding the need of a bandwidth of at least $512 \mathrm{kbps}$ and a latency of no more than $300 \mathrm{~ms}$ to conduct a satisfactory videoconference [96]. Unexpected technical issues arising with implementation should be expected, hence the importance of strong information technology support with continual protocol updating is essential [60]. We recommend thorough testing of equipment before providing service to minimize any IT glitches ensuring seamless delivery of care.

\section{c. Geriatric-specific}

Lack of technological savviness can be problematic for older adults that have not had the experience with modern technological devices. Older adults are the fastest growing population using eHealth devices [95] yet may still prefer face-to-face visits [97] making newer conventional models difficult to adopt in this population. Due to the less-personal feel of the telemedicine approach, there are inherent challenges to building rapport with patients which can be perceived as a major barrier to older adults. Geriatricians often perceive non-verbal cues and emotions, which can be inherently difficult in noticing and assessing patients' emotional reactions via telemedicine [98]. Lastly, older adults often have considerable dexterity and sensory impairments such as hearing and visual impairment [99]. An inability to manipulate the technology without assistance could be problematic, as well as cognitive impairment issues. This latter group could be considerably challenged particularly using a non face-to-face medium. However, there is insufficient evidence of weight loss in this population suggesting that this cohort of patients should be excluded from this mechanism.

\section{Additional Considerations}

\section{a. Rural health promotion}

Rural regions need special adaptations of evidencebased behavioral weight control programs. Training of lay persons as a best-practice strategy may improve health promotion efforts within such high-risk communities [100]. Such communities often have sparse healthcare resources yet close knit communities and these social networks may be helpful in disseminating evidence-based interventions [101]. Reports have indicated that adequate social support may lead to improved functional status, particularly in older adults [102, 103]. Peer networks or health coaching have the potential to improve such, despite the paucity of literature on this topic [104]. Health promotion programs have been shown to be effective in

Table 1 Practice management challenges \& proposed recommendations for coverage for medicare obesity benefit in rural areas

\begin{tabular}{|c|c|c|c|}
\hline & Current state & Barrier & Recommendation \\
\hline \multirow[t]{2}{*}{ Personnel } & $\begin{array}{l}\text { Physician, Associate Provider, } \\
\text { Clinical Nurse Specialist }\end{array}$ & $\begin{array}{l}\text { Decreased supply of PCPs creating a gap } \\
\text { in service coverage }\end{array}$ & $\begin{array}{l}\text { Allowing other healthcare providers or } \\
\text { peer-health coaching to deliver service }\end{array}$ \\
\hline & & Lack of Specialized Services Available & $\begin{array}{l}\text { Permit allied health providers in delivering } \\
\text { service from larger, specialized centers }\end{array}$ \\
\hline \multirow[t]{2}{*}{ Frequency of Visits } & $\begin{array}{l}22 \text { visits provided by above } \\
\text { personnel }\end{array}$ & $\begin{array}{l}\text { Creation of an access issue in practices } \\
\text { already overworked and overwhelmed }\end{array}$ & Maintain visit numbers \\
\hline & & & $\begin{array}{l}\text { Delegate visits to allied health providers to } \\
\text { off-set visits }\end{array}$ \\
\hline \multirow[t]{3}{*}{ Clinical Site } & $\begin{array}{l}\text { Face-to-face or Telemedicine-based } \\
\text { office setting }\end{array}$ & $\begin{array}{l}\text { Transportation issues create a barrier } \\
\text { to providing health care services }\end{array}$ & Advocate for Telemedicine in rural areas \\
\hline & & $\begin{array}{l}\text { Individuals must resident and receive } \\
\text { care in designated service areas }\end{array}$ & Eliminate requirement of service area \\
\hline & & Home-based care is not covered & Permit home-based care \\
\hline Reimbursement & G0477 Code - \$27/visit & Reduced reimbursement to providers & $\begin{array}{l}\text { Increase reimbursements or transition to } \\
\text { value-based care model }\end{array}$ \\
\hline
\end{tabular}


community-based settings among older adults engaging in physical activity [78].

\section{b. Group coaching models}

Group coaching models have often been used in corporate worlds [105] but little evidence exists within the medical setting. We believe that these models have considerable potential, including: a) a sense that group members share a common struggle and that they want to help each other (altruism); b) positive changes in some individuals can boost self-efficacy in others [106, 107]; c) group coaching may be more readily available across the population allowing for more sustainability; d) making commitments towards goals in front of others leads to a greater sense of responsibility to follow through; e) patients can use other people's tactics or attempts and apply them to themselves ("willing to try new things'). Group coaching models can be integrated both in community and healthcare settings and are a subject for future investigation.

\section{Conclusions}

The importance and value of the $\mathrm{MOB}$ in a primary care setting is evident yet a number of challenges exist that prevent its integration within routine clinical care. Telemedicine can potentially be incorporated to address rural disparities with the engagement of non-physician staff in delivering this benefit remotely but this would require changes by regulatory authorities. There is a paucity of research in telemedicine-specific geriatrics interventions and a need is required to develop pragmatic interventions needed to address this public health challenge.

\section{Abbreviations}

CMS: Centers for medicare and medicaid; IBT: Intensive behavioral therapy; MOB: Medicare obesity benefit; PCP: Primary care provider

\section{Acknowledgements}

We thank Rebecca Masutani, BA, and Heather Blunt, MBLS for their assistance with the literature search.

\section{Funding}

Dr. Batsis received funding from the Department of Medicine, DartmouthHitchcock Medical Center Junior faculty Career Award, and the Dartmouth Centers for Health and Aging (Intramural funding). The work was also supported in part by the National Institute on Aging of the National Institutes of Health under Award Number K23AG051681. The content

is solely the responsibility of the authors and does not necessarily represent the official views of the National Institutes of Health. This work was also supported by the Center for Translational Science Institute at Dartmouth (SYNERGY) UL1-TR001086, and the Dartmouth Health Promotion and Disease Prevention Research Center (Cooperative Agreement Number U48DP005018) from the Centers for Disease Control and Prevention. The findings and conclusions in this journal article are those of the authors and do not necessarily represent the official position of the Centers for Disease Control and Prevention.

Dr. Pletcher receives funding from the Health Resource Services Administration (H2ARH26029-01-00, G20RH26396) and the United States Department of Agriculture (NH0713-A17, NH0713B1).

Dr. Stahl receives funding from NIH (U01 EB012470, U54-EB015408,

1U01HL122904), AHRQ (R01 HS021681)
Availability of data and material

Not applicable.

\begin{abstract}
Authors' contributions
JAB made substantial contributions to conception and design, analysis and interpretation of data, was involved in drafting the manuscript or revising it critically for important intellectual content, and gave final approval of the version to be published. SNP made substantial contributions to conception and design, analysis and interpretation of data, was involved in drafting the manuscript or revising it critically for important intellectual content, and gave final approval of the version to be published. JES made substantial contributions to conception and design, analysis and interpretation of data was involved in drafting the manuscript or revising it critically for important intellectual content and gave final approval of the version to be published. All authors read and approved the final manuscript.
\end{abstract}

\section{Competing interests}

The authors declare that there are no conflicts of interest and none of the mechanisms that fund Batsis/Pletcher/Stahl were involved in funding this project.

\section{Consent for publications}

Not applicable.

Ethics approval and consent to participate

Not applicable.

\section{Author details}

${ }^{1}$ Section of General Internal Medicine, Dartmouth-Hitchcock Medical Center, 1 Medical Center Drive, Lebanon, NH 03756, USA. ²Geisel School of Medicine at Dartmouth, Hanover, NH, USA. ${ }^{3}$ The Dartmouth Institute for Health Policy and Clinical Practice, Lebanon, NH, USA. ${ }^{4}$ Dartmouth Centers for Health and Aging, Dartmouth College, Hanover, NH, USA. ${ }^{5}$ Health Promotion Research Center at Dartmouth, Lebanon, NH, USA. ${ }^{6}$ Dartmouth Weight and Wellness Center, Lebanon, NH, USA. ${ }^{7}$ Centers for Telehealth, Dartmouth-Hitchcock, Lebanon, $\mathrm{NH}$, USA.

Received: 18 March 2016 Accepted: 10 December 2016

Published online: 05 January 2017

\section{References}

1. Flegal KM, Kruszon-Moran D, Carroll MD, Fryar CD, Ogden CL. Trends in obesity among adults in the United States, 2005 to 2014. JAMA. 2016: 315(21):2284-91.

2. Gregg EW, Cheng YJ, Cadwell BL, et al. Secular trends in cardiovascular disease risk factors according to body mass index in US adults. JAMA. 2005; 293(15):1868-74.

3. Dowd JB, Zajacova A. Long-term obesity and physical functioning in older Americans. Int J Obes (Lond). 2015;39(3):502-7.

4. Zizza CA, Herring A, Stevens J, Popkin BM. Obesity affects nursing-care facility admission among whites but not blacks. Obes Res. 2002;10(8): $816-23$

5. Finkelstein EA, Trogdon JG, Cohen JW, Dietz W. Annual medical spending attributable to obesity: payer-and service-specific estimates. Health Aff (Millwood). 2009;28(5):w822-831.

6. Flegal KM, Graubard BI. Estimates of excess deaths associated with body mass index and other anthropometric variables. Am J Clin Nutr. 2009; 89(4):1213-9.

7. Befort CN, Nazer N, Perri MG. Prevalence of obesity among adults from rural and urban areas of the United States: Findings From NHANES (2005-2008). J Rural Health. 2012;28:392-7.

8. Glasgow N, Berry EH. Rural Aging in 21st Century America. Vol 7. 1st ed. Netherlands: Springer; 2013.

9. Sayer AA, Syddall H, Martin H, Patel H, Baylis D, Cooper C. The developmental origins of sarcopenia. J Nutr Health Aging. 2008;12(7):427-32.

10. DesRoches CM, Buerhaus P, Dittus RS, Donelan K. Primary care workforce shortages and career recommendations from practicing clinicians. Acad Med. 2015;90(5):671-7.

11. Gamm L, Hutchison L. Rural health priorities in America: where you stand depends on where you sit. J Rural Health. 2003;19(3):209-13. 
12. Gamm L, Hutchison L, Bellamy G, Dabney BJ. Rural healthy people 2010: identifying rural health priorities and models for practice. J Rural Health. 2002;18(1):9-14

13. Goins RT, Williams KA, Carter MW, Spencer M, Solovieva T. Perceived barriers to health care access among rural older adults: a qualitative study. J Rural Health. 2005:21(3):206-13.

14. MacDowell M, Glasser M, Fitts M, Nielsen K, Hunsaker M. A national view of rural health workforce issues in the USA. Rural Remote Health 2010;10(3):1531.

15. Knowler WC, Barrett-Connor E, Fowler SE, et al. Reduction in the incidence of type 2 diabetes with lifestyle intervention or metformin. N Engl J Med. 2002;346(6):393-403.

16. Look_Ahead_Research_Group. Eight-year weight losses with an intensive lifestyle intervention: the look AHEAD study. Obesity (Silver Spring). 2014; 22(1):5-13.

17. Wadden TA, Butryn ML, Hong PS, Tsai AG. Behavioral treatment of obesity in patients encountered in primary care settings: a systematic review. JAMA 2014;312(17):1779-91.

18. Batsis JA, Gill LE, Masutani RK, Adachi-Mejia AM, Blunt HB, Bagley PJ, Lopez-Jimenez F, Bartels SJ. Weight Loss Interventions in Older Adults with Obesity: A Systematic Review of Randomized Controlled Trials Since 2005. J Am Geriatr Soc. 2016. doi:10.1111/jgs.14514. [Epub ahead of print].

19. National Coverage Determination (NCD) for Intensive Behavioral Therapy for Obesity (210.12). Centers for Medicaid and Medicare Services; 2011.

20. Rueda-Clausen CF, Benterud E, Bond T, Olszowka R, Vallis MT, Sharma AM. Effect of implementing the 5As of obesity management framework on provider-patient interactions in primary care. Clin Obes. 2014;4(1):39-44.

21. Villareal DT, Chode S, Parimi N, et al. Weight loss, exercise, or both and physical function in obese older adults. N Engl J Med. 2011;364(13):1218-29.

22. Batsis JA, Huyck KL, Bartels SJ. Challenges with the Medicare obesity benefit: practical concerns \& proposed solutions. J Gen Intern Med. 2015:30(1):118-22

23. Batsis JA, Bynum JP. Uptake of the centers for medicare and medicaid obesity benefit: 2012-2013. Obesity (Silver Spring). 2016;24(9):1983-8.

24. Petterson SM, Liaw WR, Phillips Jr RL, Rabin DL, Meyers DS, Bazemore AW. Projecting US primary care physician workforce needs: 2010-2025. Ann Fam Med. 2012;10(6):503-9.

25. Lee RT, Seo B, Hladkyj S, Lovell BL, Schwartzmann L. Correlates of physician burnout across regions and specialties: a meta-analysis. Hum Resour Health. 2013;11:48.

26. Linzer M, Levine R, Meltzer D, Poplau S, Warde C, West CP. 10 bold steps to prevent burnout in general internal medicine. J Gen Intern Med. 2014:29(1):18-20.

27. Linzer M, Manwell LB, Williams ES, et al. Working conditions in primary care: physician reactions and care quality. Ann Intern Med. 2009;151(1):28-36. W26-29.

28. Yarnall KS, Pollak Kl, Ostbye T, Krause KM, Michener JL. Primary care: is there enough time for prevention? Am J Public Health. 2003;93(4):635-41.

29. Bodenheimer T, Pham HH. Primary care: current problems and proposed solutions. Health Aff (Millwood). 2010;29(5):799-805.

30. Jensen MD, Ryan DH, Apovian CM, et al. 2013 AHA/ACC/TOS guideline for the management of overweight and obesity in adults: a report of the American College of Cardiology/American Heart Association Task Force on Practice Guidelines and The Obesity Society. Circulation. 2014;129(25 Suppl 2):S102-138.

31. Caldwell PH, Arthur HM. The influence of a "culture of referral" on access to care in rural settings after myocardial infarction. Health Place. 2009;15(1):180-5.

32. Goodridge D, Hutchinson S, Wilson D, Ross C. Living in a rural area with advanced chronic respiratory illness: a qualitative study. Prim Care Respir J. 2011;20(1):54-8

33. King KM, Thomlinson E, Sanguins J, LeBlanc P. Men and women managing coronary artery disease risk: urban-rural contrasts. Soc Sci Med. 2006;62(5): 1091-102.

34. Tessaro I, Smith SL, Rye S. Knowledge and perceptions of diabetes in an Appalachian population. Prev Chronic Dis. 2005;2(2):A13.

35. Stahl JE, Dixon RF. Acceptability and willingness to pay for primary care videoconferencing: a randomized controlled trial. J Telemed Telecare. 2010; 16(3):147-51.

36. Honeycutt AA, Wile K, Dove C, Hawkins J, Orenstein D. Strategic Planning for Chronic Disease Prevention in Rural America: Looking Through a PRISM Lens. J Public Health Manag Pract. 2015;21(4):392-9.
37. Buzza C, Ono SS, Turvey C, et al. Distance is relative: unpacking a principal barrier in rural healthcare. J Gen Intern Med. 2011;26 Suppl 2:648-54.

38. FitzGerald JD, Soohoo NF, Losina E, Katz JN. Potential impact on patient residence to hospital travel distance and access to care under a policy of preferential referral to high-volume knee replacement hospitals. Arthritis Care Res (Hoboken). 2012;64(6):890-7.

39. Huang B, Dignan M, Han D, Johnson O. Does distance matter? Distance to mammography facilities and stage at diagnosis of breast cancer in Kentucky. J Rural Health. 2009;25(4):366-71.

40. Liu E, Santibanez P, Puterman ML, et al. A Quantitative Analysis of the Relationship Between Radiation Therapy Use and Travel Time. Int J Radiat Oncol Biol Phys. 2015;93(3):710-8.

41. Oleson JJ, Breheny PJ, Pendergast JF, Ryan S, Litchfield R. Impact of travel distance on WISEWOMAN Intervention attendance for a rural population. Prev Med. 2008:47(5):565-9.

42. Stephens JM, Brotherton S, Dunning SC, et al. Geographic disparities in patient travel for dialysis in the United States. J Rural Health. 2013;29(4): 339-48.

43. Kobayashi D, Otsubo T, Imanaka Y. The effect of centralization of health care services on travel time and its equality. Health Policy. 2015;119(3): 298-306.

44. Decker SL. In 2011 nearly one-third of physicians said they would not accept new Medicaid patients, but rising fees may help. Health Aff (Millwood). 2012 31(8):1673-9.

45. Jaatinen PT, Aarnio P, Remes J, Hannukainen J, Koymari-Seilonen T. Teleconsultation as a replacement for referral to an outpatient clinic. J Telemed Telecare. 2002;8(2):102-6.

46. Toledo FG, Triola A, Ruppert K, Siminerio LM. Telemedicine consultations: an alternative model to increase access to diabetes specialist care in underserved rural communities. JMIR Res Protoc. 2012:1(2):e14.

47. Wakefield BJ, Buresh KA, Flanagan JR, Kienzle MG. Interactive video specialty consultations in long-term care. J Am Geriatr Soc. 2004;52(5): 789-93.

48. Weinstein RS, Lopez AM, Joseph BA, et al. Telemedicine, telehealth, and mobile health applications that work: opportunities and barriers. Am J Med. 2014;127(3):183-7.

49. Brignell M, Wootton R, Gray L. The application of telemedicine to geriatric medicine. Age Ageing. 2007:36(4):369-74

50. Projecting the Supply and Demand for Primary Care Practitioners Through 2020. 2015; http://bhpr.hrsa.gov/healthworkforce/supplydemand/ usworkforce/primarycare/. Accessed 23 Nov 2015.

51. Hirth VA, Eleazer GP, Dever-Bumba M. A step toward solving the geriatrician shortage. Am J Med. 2008;121(3):247-51.

52. Izquierdo R, Lagua CT, Meyer $\mathrm{S}$, et al. Telemedicine intervention effects on waist circumference and body mass index in the IDEATel project. Diabetes Technol Ther. 2010;12(3):213-20.

53. West DS, Bursac Z, Cornell CE, et al. Lay health educators translate a weightloss intervention in senior centers: a randomized controlled trial. Am J Prev Med. 2011:41(4):385-91.

54. Siminerio L, Ruppert K, Huber K, Toledo FG. Telemedicine for Reach, Education, Access, and Treatment (TREAT): linking telemedicine with diabetes self-management education to improve care in rural communities. Diabetes Educ. 2014:40(6):797-805.

55. Palmas W, Teresi J, Weinstock RS, Shea S. Acceptability to primary care providers of telemedicine in diabetes case management. J Telemed Telecare. 2008;14(6):306-8

56. Tudiver F, Wolff LT, Morin PC, et al. Primary care providers' perceptions of home diabetes telemedicine care in the IDEATel project. J Rural Health. 2007;23(1):55-61.

57. Davis AM, James RL, Boles RE, Goetz JR, Belmont J, Malone B. The use of TeleMedicine in the treatment of paediatric obesity: feasibility and acceptability. Matern Child Nutr. 2011;7(1):71-9.

58. Davis AM, Sampilo M, Gallagher KS, et al. Treating rural paediatric obesity through telemedicine vs. telephone: Outcomes from a cluster randomized controlled trial. J Telemed Telecare. 2015.

59. Davis AM, Sampilo M, Gallagher KS, Landrum Y, Malone B. Treating rural pediatric obesity through telemedicine: outcomes from a small randomized controlled trial. J Pediatr Psychol. 2013;38(9):932-43.

60. Slusser W, Whitley M, Izadpanah N, Kim SL, Ponturo D. Multidisciplinary Pediatric Obesity Clinic via Telemedicine Within the Los Angeles Metropolitan Area: Lessons Learned. Clin Pediatr (Phila).2015. 
61. Irby MB, Boles KA, Jordan C, Skelton JA. TeleFIT: adapting a multidisciplinary, tertiary-care pediatric obesity clinic to rural populations. Telemed J E Health 2012;18(3):247-9.

62. Mulgrew KW, Shaikh U, Nettiksimmons J. Comparison of parent satisfaction with care for childhood obesity delivered face-to-face and by telemedicine. Telemed J E Health. 2011;17(5):383-7.

63. Schiel R, Beltschikow W, Radon S, et al. Long-term treatment of obese children and adolescents using a telemedicine support programme. J Telemed Telecare. 2008;14(1):13-6.

64. Shaikh U, Cole SL, Marcin JP, Nesbitt TS. Clinical management and patient outcomes among children and adolescents receiving telemedicine consultations for obesity. Telemed J E Health. 2008;14(5):434-40.

65. Shaikh U, Nettiksimmons J, Romano P. Pediatric obesity management in rural clinics in California and the role of telehealth in distance education. J Rural Health. 2011:27(3):263-9.

66. Gerber BS, Schiffer L, Brown AA, et al. Video telehealth for weight maintenance of African-American women. J Telemed Telecare. 2013; 19(5):266-72.

67. Pearson TA, Lewis C. Rural epidemiology: insights from a rural population laboratory. Am J Epidemiol. 1998;148(10):949-57.

68. Liou TH, Chen $\mathrm{CH}$, Hsu CY, Chou P, Chiu HW. A pilot study of videoconferencing for an Internet-based weight loss programme for obese adults in Taiwan. J Telemed Telecare. 2006;12(7):370-3.

69. Haugen HA, Tran ZV, Wyatt HR, Barry MJ, Hill JO. Using telehealth to increase participation in weight maintenance programs. Obesity (Silver Spring). 2007;15(12):3067-77.

70. Switzer JA, Demaerschalk BM, Xie J, Fan L, Villa KF, Wu EQ. Cost-effectiveness of hub-and-spoke telestroke networks for the management of acute ischemic stroke from the hospitals' perspectives. Circ Cardiovasc Qual Outcomes. 2013;6(1):18-26.

71. Arora S, Thornton K, Murata G, et al. Outcomes of treatment for hepatitis $C$ virus infection by primary care providers. N Engl J Med. 2011;364(23):2199-207.

72. McConnochie K, Wood N, Herendeen N, ten Hoopen C, Denk L, Neuderfer J. Integrating telemedicine in urban pediatric primary care: provider perspectives and performance. Telemed J E Health. 2010;16(3):280-8.

73. Aleem S, Lasky R, Brooks WB, Batsis JA. Obesity perceptions and documentation among primary care clinicians at a rural academic health center. Obes Res Clin Pract. 2015;9(4):408-15.

74. Thom DH, Ghorob A, Hessler D, De Vore D, Chen E, Bodenheimer TA Impact of peer health coaching on glycemic control in low-income patients with diabetes: a randomized controlled trial. Ann Fam Med. 2013;11(2):137-44.

75. Kumanyika SK, Fassbender JE, Sarwer DB, et al. One-year results of the Think Health! study of weight management in primary care practices. Obesity (Silver Spring). 2012;20(6):1249-57.

76. Dutton GR, Phillips JM, Kukkamalla M, Cherrington AL, Safford MM. Pilot study evaluating the feasibility and initial outcomes of a primary care weight loss intervention with peer coaches. Diabetes Educ. 2015:41(3):361-8.

77. Dorgo S, King GA, Bader JO, Limon JS. Outcomes of a peer mentor implemented fitness program in older adults: a quasi-randomized controlled trial. Int J Nurs Stud. 2013;50(9):1156-65.

78. Buman MP, Giacobbi Jr PR, Dzierzewski JM, et al. Peer volunteers improve long-term maintenance of physical activity with older adults: a randomized controlled trial. J Phys Act Health. 2011;8 Suppl 2:S257-266.

79. Bird ML, Hill KD, Robertson I, Ball MJ, Pittaway JK, Williams AD. The Association between Seasonal Variation in Vitamin D, Postural Sway, and Falls Risk: An Observational Cohort Study. J Aging Res. 2013;2013: 751310.

80. Johansen A, Boulton C, Neuburger J. Diurnal and seasonal patterns in presentations with hip fracture-data from the national hip fracture database. Age and Ageing August. 2016;1:2016.

81. Stut W, Deighan C, Cleland JG, Jaarsma T. Adherence to self-care in patients with heart failure in the Heart Cycle study. Patient Prefer Adherence. 2015;9:1195-206.

82. Ciere Y, Cartwright M, Newman SP. A systematic review of the mediating role of knowledge, self-efficacy and self-care behaviour in telehealth patients with heart failure. J Telemed Telecare. 2012;18(7):384-91.

83. Ellis I, Cheek C, Jaffray L, Skinner T. Making a case for telehealth: measuring the carbon cost of health-related travel. Rural Remote Health. 2013;13(4):2723.
84. Befort CA, Donnelly JE, Sullivan DK, Ellerbeck EF, Perri MG. Group versus individual phone-based obesity treatment for rural women. Eat Behav. 2010;11(1):11-7.

85. Befort CA, VanWormer JJ, DeSouza C, et al. Protocol for the Rural Engagement in Primary Care for Optimizing Weight Reduction (RE-POWER) Trial: Comparing three obesity treatment models in rural primary care. Contemp Clin Trials. 2016;47:304-14.

86. Perri MG, Limacher MC, von Castel-Roberts $K$, et al. Comparative effectiveness of three doses of weight-loss counseling: two-year findings from the rural LITE trial. Obesity (Silver Spring). 2014;22(11):2293-300.

87. Ely AC, Banitt A, Befort C, et al. Kansas primary care weighs in: a pilot randomized trial of a chronic care model program for obesity in 3 rural Kansas primary care practices. J Rural Health. 2008;24(2):125-32.

88. Thomas JG, Leahey TM, Wing RR. An automated internet behavioral weightloss program by physician referral: a randomized controlled trial. Diabetes Care. 2015;38(1):9-15.

89. O'Brien T, Jenkins C, Amella E, Mueller M, Moore M, Hathaway D. An Internet-Assisted Weight Loss Intervention for Older Overweight and Obese Rural Women: A Feasibility Study. Comput Inform Nurs. 2016; 34(11):513-9.

90. Perri MG, Limacher MC, Durning PE, et al. Extended-care programs for weight management in rural communities: the treatment of obesity in underserved rural settings (TOURS) randomized trial. Arch Intern Med. 2008:168(21):2347-54

91. Mulrow CD, Aguilar C, Endicott JE, et al. Association between hearing impairment and the quality of life of elderly individuals. J Am Geriatr Soc. 1990;38(1):45-50.

92. Wingfield A, Lindfield KC, Goodglass $\mathrm{H}$. Effects of age and hearing sensitivity on the use of prosodic information in spoken word recognition. J Speech Lang Hear Res. 2000;43(4):915-25.

93. McCracken PR. Getting into telemedicine: information for physicians. Geriatr Aging. 2005;8:67-71.

94. Wager K, Lee F, Glaser J. Managing Health Care Information systems. San Francisco: Jossey-Bass; 2005.

95. Administration on Aging. Internet Usage and Online Activities of Older Adults. 2013. Accessed 23 April 2013, 2013

96. Schulz TR, Richards M, Gasko H, Lohrey J, Hibbert ME, Biggs BA. Telehealth: experience of the first 120 consultations delivered from a new refugee telehealth clinic. Intern Med J. 2014:44(10):981-5.

97. Costa PD, Reis AH, Rodrigues PP. Clinical and economic impact of remote monitoring on the follow-up of patients with implantable electronic cardiovascular devices: an observational study. Telemed J E Health. 2013;19(2):71-80.

98. Starren J, Hripcsak G, Sengupta S, et al. Columbia University's Informatics for Diabetes Education and Telemedicine (IDEATel) project: technical implementation. J Am Med Inform Assoc. 2002;9(1):25-36.

99. Inouye SK, Studenski S, Tinetti ME, Kuchel GA. Geriatric syndromes: clinical, research, and policy implications of a core geriatric concept. J Am Geriatr Soc. 2007:55(5):780-91.

100. Smedley DD, Stith AY, Nelson AR. IOM (US) Committee on Understanding and Eliminating Racial and Ethnic Disparities in Health Car. Unequal treatment: confronting racial and ethnic disparities in healthcare. Washington, DC: National Academy Press; 2003.

101. Raczynski JM, Cornell CE, Stalker V, et al. Developing community capacity and improving health in African American communities. Am J Med Sci. 2001:322(5):294-300.

102. Pavela G. Functional status and social contact among older adults. Res Aging. 2015;37(8):815-36.

103. White AM, Philogene GS, Fine L, Sinha S. Social support and self-reported health status of older adults in the United States. Am J Public Health. 2009; 99(10):1872-8

104. van der Bij AK, Laurant MG, Wensing M. Effectiveness of physical activity interventions for older adults: a review. Am J Prev Med. 2002;22(2):120-33.

105. Kampa-Kokesch S, Anderson MZ. Executive coaching: a comprehensive review of the literature. Consult Psychol J: Pract Res. 2001;53(4):205-28.

106. Caldwell KL, Gray J, Wolever RQ. The Process of Patient Empowerment in Integrative Health Coaching: How Does it Happen? Glob Adv Health Med. 2013;2(3):48-57.

107. Edelman D, Oddone EZ, Liebowitz RS, et al. A multidimensional integrative medicine intervention to improve cardiovascular risk. J Gen Intern Med. 2006;21(7):728-34 